\title{
Comparative Analysis of Domestic and Foreign Management Science and Engineering Research Hot Issues
}

\author{
Yincheng Wang
}

Beijing zhongke hengxin technology co. LTD, Beijing, 100085, China

\begin{abstract}
Keywords: Management science, Engineering research, Forecasting technology.
\end{abstract}
\begin{abstract}
With the continuous development of modern society, great progress has been made in management science and engineering research. Especially since the reform and opening up, the development of all aspects has been very rapid. Therefore, this paper analyzes the hot issues in management science and engineering at home and abroad. First of all, the status of domestic and foreign management science and engineering research is described, followed by the analysis of domestic and foreign management science and engineering research hot issues. Again, the differences between management science and engineering research both at home and abroad are analyzed and studied. Finally, according to the content of the analysis and research, the author expounds the comparative enlightenment of the research hot issues and draws more meaningful conclusions. The author hopes that through the analysis and research of this paper, provide some advice and reference for the management science and engineering research subject and the activities of independent main body, to promote the development and progress of management science and engineering research.
\end{abstract}

\section{Introduction}

With the development of modern society, people have a deeper understanding and elaboration of the definition of management science. Management science is a science to study the universal and objective laws in the process of management. With the development of management science, the definition of management science in China not only has a broad definition and narrow definition, but China mainly recognizes the broad category. The so-called broad category is different in understanding from the foreign narrow understanding of management science. The development of foreign management science mainly goes through three stages of development, which are mainly the stage of scientific management, stage of behavioral science and stage of management jungle. However, the development of management science in China has also gone through three stages of development. The first stage: before the reform and opening up, it mainly copied the Soviet Union mode. Therefore, we also call this stage as imitating the Soviet Union stage. This stage belongs to the development stage that China established management science. The second stage: From 1977 to 1995, China's scientific management gained development. The third stage: the current stage of prosperity and innovation. The development of management science in China still has a big difference compared with that in other countries. China was later than the western countries for the time entered the stage of scientific management and management jungle. In terms of research content, there are also big differences between China and the western countries.

\section{Status quo of researches}

\section{Analysis of the Current Situation of Management Science and Engineering in Foreign Countries}

This paper analyzes the current situation of foreign management science and engineering research, mainly through factor analysis and other relevant data as the basis, and then selects 59 representative foreign journals for analysis and study, and finally keywords are used to retrieve related papers, on 
this basis, analysis is conducted for the status quo of foreign management science and engineering research.

We analyze from the total, the main contents of foreign management science and engineering researches mainly include the following aspects: first of all, decision-making and countermeasures theory, organizational theory, operations management and management; followed by information technology and management, management systems engineering, evaluation techniques, complexity studies and general management theories. However, in the process of foreign management science and engineering researches, there are few researches on the studies on the history of management thinking, theories of management psychology and behavior, forecasting techniques, quantitative economic analysis methods and industrial engineering, and also few papers and journals in this area through searching. This situation is mainly due to the fact that there has been a change in the focus of management science and engineering abroad since the Second World War to the 1970s. The research focuses mainly on quantitative analysis methods such as operations research and systems engineering, mainly to greatly improve the accuracy of decision-making and the efficiency of management, moreover, the research on this aspect of content is often able to get people's attention and financial support. Therefore, the focus of research is mainly concentrated on this aspect. For the study of industrial engineering, forecasting technology and quantitative economic analysis methods, more is to study from the engineering point of view and economic point of view, the history of management thought, management psychology and behavior theory have not got support from other new disciplines as well as reform of related tools in the process of research; and also got few related funds in the research process, thus study of this content continues to weaken.

Analyzing the research on management science and engineering in foreign countries from the longitudinal laws of historical change, we find that the number of dissertations in all fields of management science and engineering continues to increase over time, especially in the period from 1990 to 1992. The growth of the number of theses is the most obvious. After that, the growth of the number of the papers gradually enters into a period of steady development. In all areas of management science and engineering research, the growth of the number of papers in the three fields of decision-making and countermeasure theory, organizational theory and operations and management is the most obvious. However, an analysis based on the research trends shows that operations and management, information technology and management will continue to get the attention of researchers, and will continue to maintain the upward trend, the growth of number of papers is also more substantial.

\section{Analysis of the Current Situation of Management Science and Engineering in China}

First of all, if we analyze and study the total amount, we find that the main contents of the research of management science and engineering in our country are quite different from those in western countries. The contents of the research mainly focus on both information technology and management and management systems. In addition to these two aspects, but also focus on forecasting techniques, assessment techniques and operations management these three aspects, but lack of history of management science and management thinking, management psychology and behavioral theory and complexity research. There are only 20 relevant research papers, and it has not formed the mainstream of the study. The main reason for this phenomenon is that the profound influence of information technology in China and the strategy of informatization in China have been paid more and more attention in the fields of management science and engineering research. Along with the continuous development of social economy in China, the information technology development, enterprise informatization, decision-making system and government informatization has been combined with practice, and has achieved good results and produced great economic benefits. Therefore, the research in this field has gradually become the mainstream. Although the emergence of system theory has been around for more than a century in foreign countries, it is a relatively new field in China because system theory study is late in China. However, the combination of system theory and management isses has gradually been focused by researchers and the related research results are 
also emerging with abundant results. Research on the field of management science and engineering, such as forecasting technology, assessment technology, and operational research and management, has been re-tested by practice and has gained a great deal of development when it comes to resolving new business problems and socio-economic issues.

From the longitudinal analysis of the law of historical change, we find that every field of management science and engineering research in our country has been more or less developed, and the number of papers shows an increasing trend, especially in information technology and management, management system engineering and the development of forecasting techniques and assessment techniques, the increase in the number of papers is obvious. Not only that, the number of papers published in most of management science and engineering research fields has been increasing, but the trend of the number of papers is not very stable and the gap is relatively large. The main reason for this phenomenon is affected by the relevant state policies and changes in the funding environment, which is very unfavorable for the research and development of disciplines. In addition to these impacts, we found through research that in 1996 and 1999 there was a peak in the growth of the number of papers. And because there was no longer time-series data to serve as an empirical evidence, the author speculated that the management science and engineering research in China takes three years to get a breakthrough development. Therefore the research funding structure of management science and engineering in China should at least cover the period of three years or more when formulating the related funding plan.

\section{Comparative analysis of research hot spots}

In fact, the so-called research hot spot is mainly reflected in a certain period of time, the concerns of academic community on a number of specific issues. In the course of our research, we can use the number of papers published in a particular field or the frequency of keyword occurrences when searching keywords. This also shows the emphasis on a particular theoretical study. Hot issues mainly emerge with the social practice needs and research, and also followed by constantly changing. We study the hot issues and mainstream areas which is consistent that is to say, a problem becomes a hot issue, it will inevitably lead to academic and relevant scholars' attention, and then researched by scholars, so that makes this hot issue into the mainstream field of research.

\section{Hot issues of foreign researches}

If we continue to pay attention to a problem and cause widespread concern in society, it will inevitably make this issue a priority for scholars and experts in relevant fields, arouse the study of scholars and experts, which in turn will make this hot issue become mainstream in this field. Through the analysis of foreign management science and engineering research papers for nearly ten years, the author found that the foreign management science and engineering hot issues are focused on the general management of knowledge management issues, management system, the philosophical attributes of research and team management and information management methodology these aspects.

\section{Hot issues of domestic researches}

With the development of China's society and economy, especially since the reform and opening up, the opening up of China has been deepening and the development of the socialist market economy. The role played by modern scientific management theories in China's management practices has been deepening and gaining increasingly attention by academic communities and theorists. Therefore, this study focuses on the hot issues of management science and engineering research in China, mainly based on the papers and research results of the past decade. It is found that the hot issues in recent years in our country mainly focus on human management theory, management model, the initial theory of knowledge management and knowledge-based management incentives, and for the 
operation and management of dynamic programming, linear programming, production system inventory optimization theory is under various conditions, the research for which is at a disadvantage.

\section{Analysis of differences in research}

After the analysis of management science and engineering research at home and abroad, the differences between China and foreign countries are mainly reflected in the following aspects:

(1) In the fields of foreign management science and engineering research, the research on knowledge management and complexity research has made great achievements and obtained great development. However, due to the relatively late introduction in China, it has not become hot issues of research by now. However, with the continuous development, it will become the hotspot of China in the near future. This is an inevitable trend of development.

(2) Researches on the history of management thinking, management theory and behavior theory and other aspects have been increasingly reduced in both China and foreign countries while the area of research is also constantly shrinking. If we do not improve and complete the contents with the help of other subjects in this area, it will be difficult to arouse the attention of academics and researchers in the future and will not get greater development in the future.

(3) As far as the current situation is concerned, there is not much difference between domestic and foreign researches on information technology and management, decision-making and countermeasure theory.

\section{Enlightenment of research hot spots comparison.}

With the development of modern society and the continuous expansion of the field of management science and engineering research, the mainstream of research is increasingly influenced by the information technology, science and technology and economic integration of modern society. It is precisely because of the development of information technology, science and technology and Internet technology, it have brought new opportunities and challenges to the mainstream areas of management science and engineering research and promoted the development and progress of management science and engineering research.

With the development of society and economy, especially the practice of management science and engineering in modern society, some fields of study have been gradually shrinking. Even some areas of research have been eliminated by society, such as the theory of management psychology and behavior theory, but so at the same time, with the continuous development of society, new research fields have emerged, such as complexity studies and e-commerce. Therefore, it is necessary for domestic researchers to keep track of and study the latest research trends, to cultivate the agility of scholars and researchers to discover and analyze research hotspots.

In modern society, most of the hot issues in management science and engineering research come from the needs of social management practice, which is what we call the problem orientation and focus on technology and operability, so this requires the relevant researchers and research subjects in China shall pay more attention and emphasis on management practices, rather than for research.

Compared with foreign countries, China should strengthen the funding for hot issues, especially related to the funding structure should be strengthened in this regard, mainly because of research focus and management practices are closely linked together, it is easy to produce economic benefits during manage practice process, especially for some hot issues in China and abroad. The research field of these hot issues plays an important role for China's management science research.

\section{Conclusions}

This paper mainly elaborates the comparative analysis of the hot issues of management science and engineering in China and abroad. With the development of modern society, the role of management 
science in practice is more and more important. However, the research for some fields was started late, thus in the process of research, we need to learn from the experience and lessons of foreign development. The author compares the differences between domestic and foreign research which is based on this purpose. I hope this paper can provide some references to promote the development and progress of management science in China.

\section{References}

[1] Zou Shuliang, Zhang Caiping. Research on the Compound Cultivation Mode of Graduate Management Science and Engineering Graduate Students, Journal of Hunan University of Science and Technology, 2010(05).

[2] Xu Chunyan, Zhang Yali. Tendency of Master Thesis in Management Science and Engineering and Research Tendency, Scientific era, 2010(12). 